\title{
CHEMICAL COAGULATION OF COMBINED SEWER OVERFLOW: HEAVY METAL REMOVAL AND TREATMENT OPTIMIZATION
}

\author{
A.G. EI Samrani\#, B. S. Lartiges ${ }^{*}$, F. Villiéras \\ Nancy University - LEM-ENSG/INPL-CNRS - Pôle de l'Eau \\ 15, Avenue du Charmois - BP 40 - F-54 501 Vandœuvre Cedex - FRANCE \\ E-mail: bruno.lartiges@get.omp.eu
}

(*) To whom correspondence should be addressed

(\#) Present address: University St Esprit Kaslik - Jounieh - LEBANON 


\begin{abstract}
The coagulation of Combined Sewer Overflow (CSO) was investigated by jar-testing with two commercial coagulants, a ferric chloride solution (CLARFER) and a polyaluminium chloride (WAC HB). CSO samples were collected as a function of time during various wetweather events from the inlet of Boudonville retention basin, Nancy France. Jar-tests showed that an efficient turbidity removal can be achieved with both coagulants, though lower optimum dosages and higher re-stabilization concentrations were obtained with the aluminum-based coagulant. Optimum turbidity removal also yielded effective heavy metal elimination. However, the evolution with coagulant dosage of $\mathrm{Cu}, \mathrm{Zn}, \mathrm{Pb}, \mathrm{Cr}$, soluble and suspended solids contents followed various patterns. The removal behaviors can be explained by a selective aggregation of heavy metal carriers present in CSO and a specific interaction between hydrolyzed coagulant species and soluble metals. Stoichiometric relationships were established between optimal coagulant concentration, range of optimal dosing, and CSO conductivity, thus providing useful guidelines to adjust the coagulant demand during the course of CSO events.
\end{abstract}

\title{
Keywords
}

combined sewer overflow, heavy metal removal, coagulation, ferric chloride, PAC, alkalinity 


\section{INTRODUCTION}

Combined sewer overflow (CSO) is a major environmental concern in cities with a combined sewer system. During a CSO event, the discharge of untreated domestic sewage and stormwater into local waterways represents a large input of nutrients, organic matter, contaminants, pathogens, debris... This causes immediate and long-term damages (aesthetic pollution, reduced levels of dissolved oxygen and increased fish mortality, micro-pollutant accumulation inside living species, degradation of water resources, eutrophication...) to the receiving aquatic ecosystem (Paulson and Amy, 1993, Chebbo et al., 1995, Marsalek et al., 1999).

In cities where the existing drainage systems can not be easily upgraded, CSOs can be controlled by storing the excess flows in retention basins for later redistribution to the combined sewer and to the wastewater treatment plant. Retention basins can also be used for removing particulate matters by sedimentation. In that case, the efficiency of suspended solid removal can reach $60 \%$ to $80 \%$ for a settling velocity of about $0.03 \mathrm{~m} / \mathrm{min}$ (Cole and Yonge, 1993; Bridoux et al., 1998; Nascimento et al., 1999). However, such a removal essentially concerns particles greater than $50 \mu \mathrm{m}$ (Hamilton et al., 1984; Badard et al., 1994), whereas heavy metals present in CSOs and stormwaters are predominantly associated with the finer particles and colloids (Ellis and Revitt, 1982; Hamilton et al., 1984; Grout et al., 1999; El Samrani et al., 2004a). In most cases, heavy metal removal by settling does not exceed 28 to $40 \%$ (Cole and Yonge, 1993). Moreover, retention basins can sometimes be undersized and the overflows from major wet weather events are still discharged to the nearby water bodies. With the potential of significant changes in rainfall patterns due to climate change, the choice of an adequate storage capacity is then critical.

An alternative approach to control overflows is in-line treatment. In that case, an enhanced removal of contaminants can be achieved by chemical coagulation and subsequent settling, before discharging treated CSO to the receiving waters. Typical removal efficiencies reported for pilot-scale tests are consistently around $90 \%$ for suspended solid and about $60 \%$ for chemical oxygen demand (Delporte et al., 1995; Plum et al. 1998; Westrelin and Bourdelot, 2001). However, two key problems must be addressed for a successful full-scale treatment. First, the time needed to reach a steady-state operation, referred to as «start-up», takes about 15 to 20 minutes, which is significant for a CSO that may last less than 30 minutes (Delporte et al., 1995). As a result, the «first flush», which usually corresponds to the most polluted flows (Morisson et al., 1984), can be missed before an efficient coagulation can be obtained. Secondly, during CSO treatment, the physicochemical characteristics of the 
raw water dramatically vary as a function of time (Gruber et al., 2005); as a consequence, coagulant dosage must be adjusted accordingly to maintain optimal treatment conditions.

The basic objectives of this study were then (i) to investigate CSO chemical coagulation from jar-tests during various wet-weather events (ii) to assess process efficiency for heavy metal removal, (iii) and to develop quantitative relationships between optimal coagulant conditions and CSO physico-chemical characteristics to provide control tools for an efficient in-line CSO full-scale treatment.

\section{EXPERIMENTAL SECTION}

\section{Sample collection}

The study site, Boudonville catchment area, is located in the north-west part of the city of Nancy (France); it receives runoff from 246 ha of urban surfaces $(\sim 20000$ inhabitants) through a combined sewer system (El Samarani et al., 2004a). The average slope of the watershed is $0.034 \mathrm{~m} / \mathrm{m}$ with $40 \%$ of impervious surface (Marchand et al., 1993). Boudonville watershed is equipped with eight rain-gauges and 20 limnimeters, and has been used as an experimental catchment area for hydraulic and pollution transport studies over the past two decades (Marchand et al., 1993, Laurensot, 1998, El Samrani et al., 2004a).

During rain events, CSO samples were taken as a function of time from the inlet of Boudonville retention basin with a peristaltic pump (Delasco $\mathrm{Z}$ - flow rate $5 \mathrm{~L} / \mathrm{min}$ ) every 5 10 minutes. For comparison of treatment conditions, grab-samples of sewage were also collected from the nearby "liberation" trunk in dry weather conditions. The samples were collected into $10 \mathrm{~L}$ polyethlylene jerrycans, transported to the laboratory, and used for jar-test experiments within 3 hours of sampling. After gentle over-end agitation of jerrycans, a $1 \mathrm{~L}$ sample of raw water was taken for characterization. Conductivity and $\mathrm{pH}$ were measured under slow magnetic stirring by using a calibrated CD810 conductimeter and a 210 Taccussel pH-meter. Suspended Solids (SS) was obtained by drying a duplicate of $10 \mathrm{~mL}$ well-mixed CSO sample at $105^{\circ} \mathrm{C}$ for 5 hours. Volatile solid (VS) content was determined by further heating the same samples at $550^{\circ} \mathrm{C}$ for 3 hours. Total alkalinity was assessed by titrating 100 $\mathrm{mL}$ of filtered raw water (Whatman filter paper 42) to $\mathrm{pH} 4.3$ with a $10^{-2} \mathrm{M} \mathrm{H}_{2} \mathrm{SO}_{4}$ solution (Rodier, 1984).

\section{Jar-test experiments}


Two commercial coagulants, CLARFER and WAC HB (ARKEMA, France), were used in this study. CLARFER is an unhydrolyzed ferric chloride solution, $38 w t \%$ in $\mathrm{FeCl}_{3}$ with a density of 1.4. WAC-HB is a partially neutralized aluminum salt solution of $\mathrm{pH} 3.1$ and contains about 8.84 wt \% of aluminum as $\mathrm{Al}_{2} \mathrm{O}_{3}, 1.52$ wt \% of $\mathrm{SO}_{4}{ }^{2-}, 7.14$ wt $\%$ of $\mathrm{Cl}^{-}$, and $1.33 w t \%$ of $\mathrm{Ca}^{2+}$.

The coagulation tests were conducted in standard $1 \mathrm{~L}$ glass beakers $(90 \mathrm{~mm}$ diameter, $150 \mathrm{~mm}$ high) fitted with four plexiglass baffles $(12 \mathrm{~mm} \times 150 \mathrm{~mm}) .1 \mathrm{~L} \mathrm{CSO}$ samples were taken from the jerrycans and stirred with a $15 \mathrm{~mm}$ x $54 \mathrm{~mm}$ blade positioned at one-third of the reactor height from the bottom. The stirring rate was fixed at $100 \mathrm{rpm}$ which corresponds to a mean velocity gradient $\mathrm{G}=135 \mathrm{~s}^{-1}$. The coagulant was added under agitation as pure solution using a micro-pipette (Ependorf) at a point just below the free surface of the suspension. After 20 minutes mixing at $100 \mathrm{rpm}$, the coagulated suspensions were allowed to settle in graduated Imhoff cones for 30 minutes.

\section{Supernatant characterization}

After settling, sediment volume was measured and about $60 \mathrm{~mL}$ of supernatant were siphoned with a syringe from about $25 \mathrm{~mm}$ below the surface. Conductivity, $\mathrm{pH}$, and residual turbidity (Hach XR ratio turbidimeter) were first measured. $25 \mathrm{~mL}$ of supernatant were then filtered through a $0.22 \mu \mathrm{m}$ pore size cellulose-acetate filter (Macherey-Nagel filter) for measuring dissolved trace elements in the supernatant. It should be pointed out that the fraction lower than $0.22 \mu \mathrm{m}$ contains dissolved metals as well as colloidal particles. Still, such fraction will be referred to as soluble fraction hereafter. Another $25 \mathrm{~mL}$ of supernatant was acidified with $10 \mathrm{~mL}$ of $\mathrm{HNO}_{3}(7 \mathrm{M})$ to obtain the total amount of trace elements in the supernatant. The difference between total metal concentration and soluble metal concentration yielded the amount of trace elements associated with residual suspended solids. Filtrates were acidified with $\mathrm{HNO}_{3}$ and stored at $4{ }^{\circ} \mathrm{C}$ prior to analysis with ICP-MS (Perkin Elmer 5000 mass spectrometer). The experimental error is less than $10 \%$ in the range of measured concentrations. The detection limits are $0.224 \mu \mathrm{g} / \mathrm{L}$ for $\mathrm{Cu}, 0.282 \mu \mathrm{g} / \mathrm{L}$ for $\mathrm{Cr}, 0.02 \mu \mathrm{g} / \mathrm{L}$ for $\mathrm{Pb}$, and $0.027 \mu \mathrm{g} / \mathrm{L}$ for $\mathrm{Zn}$. For some jar-tests, the eletrophoretic mobility of unsettled aggregates was determined with a Zetaphoremeter III (El Samrani et al., 2004b).

\section{RESULTS AND DISCUSSION}


25 rain events were sampled during the period of the study. They can roughly be divided into two types: storm events corresponding short and intense rainfalls that occur during spring and summer, and weak rain events associated with long lasting rain of low intensity (fall and winter). Even though the quality of effluents was found to vary markedly during a single rain event, such a typology is reflected in the mean physicochemical characteristics of CSO (Table 1). Typical CSO resulting from storm events are characterized by a high turbidity and contents in suspended solids similar to that of dry weather flow. Nevertheless, such CSO does not simply result from wastewater mixed with runoff from urban surfaces, but essentially originates from the erosion of sewer sediments (GromaireMertz et al., 1998; Tait et al., 1998; Gromaire et al., 2001; El Samrani et al., 2004a). In comparison, CSO asociated with weak rain events show much lower turbidity and SS concentrations. Furthermore, both $\mathrm{pH}$ and total alkalinity of CSO from weak rain events are consistently lower than those of CSO from storms, which are themselves significantly lower than those of dry weather flow (Table 1).

\section{Turbidity removal}

A total of 53 jar tests were conducted (32 of them with ferric chloride). The results of jar-tests carried out with dry weather sewage are reported in a separate paper (E1 Samrani et al., 2004b). Typical curves obtained during coagulation of combined sewer overflow are presented in figures 1 and 2. Figure 1 compares the performance of CLARFER and WAC HB in terms of turbidity removal and sediment volume for a rain event yielding overflows of high alkalinity. For both coagulants, the residual turbidity decreases continuously to reach a similar minimal value at intermediate dosages, whereas sediment volume increases almost linearly with coagulant concentration. However, the initial drop in turbidity is less pronounced with ferric chloride and the suspension is restabilized at high Fe concentration. The optimum coagulant concentrations (OCC), defined as the minimum dosage needed to attain the low residual turbidity value, are indicated on the graph by an arrow. WAC HB is clearly more effective than CLARFER for turbidity removal, especially as equivalent sludge volumes are generated at OCCs. Interestingly, sludge volume keeps increasing proportionally to the amount of added coagulant beyond OCC. Such behavior can be attributed to a sweepflocculation mechanism (Gregory and Dupont, 2001), or to an heteroaggregation of CSO particles with coagulant species increasing in size (El Samrani et al., 2004b).

A slightly different pattern is obtained for CSO with low alkalinity (figure 2). In that case, the turbidity removal is retarded at low coagulant concentrations, whereas restabilization 
of CSO suspensions is observed for both coagulants. On the other hand, settled volume rapidly increases just before OCC and sharply diminishes upon restabilization. This restabilization may be related to the drop in $\mathrm{pH}$ occurring when coagulant hydrolysis exceeds the buffer capacity of the suspension: the overall negative charge of natural organic matter should then decrease while the number of positive coagulant species continues to increase, thus inducing restabilization of the suspension. Electrophoretic mobility measurements further corroborate the occurrence of charge neutralization (fig. 2a-2c). Although the addition of either CLARFER or WAC-HB only slightly reduces the negative charge of CSO aggregates at OCC, the restabilization of the suspension coincides with the charge reversal of particles. Similar results have been reported for municipal sewage coagulated either with alum (Ghosh et al., 1994) or with ferric chloride (El Samrani et al., 2004b), and for humic substances aggregated with $\mathrm{Al}_{13}$ polycations (Kazpard et al., 2006). According to Kazpard, this behavior originates from a charge neutralization of organic macromolecules rearranging around positive coagulant species such that the negative charge of functional groups remains displayed to the bulk until charge balance is obtained at the onset of restabilization domain (Kazpard et al., 2006).

\section{Heavy metal removal}

Heavy metal removal was studied from samples collected in 7 different CSO, 5 of them storm events. Figure 3 shows the typical evolution of $\mathrm{Cu}, \mathrm{Pb}, \mathrm{Zn}$, and $\mathrm{Cr}$ concentrations in both soluble and residual suspended solids fractions as a function of $\mathrm{Al}$ or Fe dosage. The $\mathrm{x}$-axes were normalized with regards to the respective OCCs in order to highlight any difference in heavy metal removal behavior between the two coagulants. Also plotted in most graphs is the supernatant residual turbidity, the $y$-axis being adjusted to match the evolution of heavy metal concentration in residual suspended solids. The control experiments (stirring and settling without added coagulant) revealed that the supernatant concentrations in $\mathrm{Cu}, \mathrm{Zn}$, and $\mathrm{Pb}$ (dissolved and suspended solids fractions) represent respectively 69,85 and $50 \%$ of total metal concentrations.

As illustrated in figure $3 \mathrm{a}-\mathrm{d}, \mathrm{Cu}$ and $\mathrm{Pb}$ exhibit a similar removal behavior for both $\mathrm{Al}$ and Fe coagulants: the soluble fraction is eliminated at a [coagulant]/OCC ratio less than 1, whereas the particulate fraction closely follows the residual turbidity curve even during restabilization for the iron-based coagulant. In contrast, the suspended solid fraction associated with $\mathrm{Zn}$ is less effectively removed than turbidity at low coagulant concentrations, whereas particulate $\mathrm{Cr}$ is not coagulated at all in the underdosage range with both CLARFER 
and WAC HB. Furthermore, both soluble $\mathrm{Zn}$ and $\mathrm{Cr}$ increase above $\mathrm{OCC}$ to reach concentrations greater than the respective initial supernatant concentrations. Nevertheless, it should be pointed out that, except for $\mathrm{Cr}$, at the optimal dosage defined as that producing a low turbidity, both coagulant provided excellent heavy metal removal since the residual concentrations in $\mathrm{Cu}, \mathrm{Zn}$ and $\mathrm{Pb}$ in the clarified water comply with the legislation for potable water (ASTEE, 2006).

The observed removal behaviors for suspended solids may be explained by a selective aggregation of heavy metal carriers during coagulation. A previous report showed that, in $\mathrm{CSO}, \mathrm{Cu}$ is primarily found as sulfide species $\left(\mathrm{CuS}, \mathrm{CuFeS}_{2}, \ldots\right), \mathrm{Pb}$ is mainly present as $\mathrm{Pb}$ monosulfide and $\mathrm{PbSn}$ alloy, $\mathrm{Zn}$ is predominantly encountered as sulfide and phosphate phases, whereas $\mathrm{Cr}$ is generally observed within stainless steel and iron oxihydroxide particles (El Samrani et al., 2004a). In the pH range of jar-test experiments [4-7.5], iron oxihydroxides and phosphate phases such as apatite are positively charged (Chander and Fuerstenau, 1979), whereas pristine sulfide particles are expected to be negatively charged (e.g. Bebie et al., 1998). However, it should be noted that the gradual oxidation of metal sulfides can significantly alter the surface charge development; for instance, the point of zero charge (PZC) of pyrite shifts from 1.2 to 7 upon oxidation (Fornasiero et al., 1991), whereas a value of 8.5 has been reported for the PZC of ZnS (Pugh and Tjus, 1987). As the coagulant species formed upon hydrolysis of iron and aluminum commercial solutions are positively charged (El Samrani et al. 2004b), the poor or retarded removal evidenced for $\mathrm{Cr}$ and $\mathrm{Zn}$ suspended solids may be related to the alike surface charge of carriers. Similarly, the two stage removal observed for $\mathrm{Pb}$ and $\mathrm{Zn}$ particles with the aluminum-based coagulant (fig. 3d and $3 \mathrm{f}$ ), can be explained by the successive removal of two different heavy metal carriers.

On the other hand, the elimination at low coagulant concentrations of $\mathrm{Cu}, \mathrm{Pb}$, and $\mathrm{Zn}$ soluble fractions suggests an uptake of these elements by the iron or aluminum hydrolysis products. Indeed, the sorption of these heavy metals to iron or aluminum oxihydroxides mineral phases has been shown to occur in a wide range of conditions (Herbert Jr., 1996; Spadini et al., 1994; Martinez et al., 1998). The strong increase in soluble $\mathrm{Zn}$ and Cr observed above OCC with CLARFER application, may result from various phenomena. First, the decrease in $\mathrm{pH}$ originating from the formation of hydrolyzed coagulant species may promote the dissolution of coagulated and settleable heavy metal carriers. Then, in the case of $\mathrm{Zn}$, the interaction of hydrolyzed iron(III) with Zn-sulfide surface may induce some oxidative dissolution (Richmond et al., 2005). Finally, exchangeable $\mathrm{Zn}$ and $\mathrm{Cr}$ associated with clays and functional groups of organic matter may be replaced by the excess of iron-coagulant 
species (Jung et al., 2005), although this latter hypothesis is not supported by the data obtained with WAC HB (fig. 3).

\section{Optimization of coagulant dosing}

As shown above, coagulant overdosing leads to a restabilization of the suspension and therefore, to a release in heavy metal in the treated water. As the quality of CSO continuously changes with time (Lainé et al. 1998; Gruber et al., 2005; Suarez and Puertas 2005), the application of an appropriate coagulant concentration is critical. Figure 4 shows the results of two series of jar-test conducted with CLARFER and WAC HB on CSO samples collected as a function of time from two different rain events. In both cases, the initial jar-test was carried out with dry weather sewage. The same general evolution can be described for both coagulants: as overflow starts, OCC sharply decreases towards lower coagulant concentration, while concomitantly, a narrower range of optimal dosing is observed. Therefore, an optimal coagulant concentration at a given moment can turn out to be a restabilization concentration a few minutes later (insets of fig. 4).

Such a rapid evolution of OCC is explained by a change in CSO physicochemical characteristics with time. As illustrated in figure 5, parameters that are relevant to CSO treatability such as suspended solids, turbidity, $\mathrm{pH}$, and conductivity, exhibit a complex dynamics. Thus, at the beginning of the CSO event, flow rate abruptly increases whereas SS slightly rises; it then peaks with flow rate, gradually diminishes for some time, and strongly re-increases while flow rate keeps decaying back to the dry weather regime. A previous study revealed that these two successive increases in SS can be attributed to sewer sediment resuspension and urban surface wash-off, respectively (El Samrani et al., 2004a). In parallel, conductivity substantially decreases in two steps whereas $\mathrm{pH}$ and turbidity roughly diminish with time.

Therefore, maintaining an optimal CSO treatment implies a continuous adjustment of coagulant concentration. Until now, such monitoring has generally been performed from measurements of SS or CSO initial turbidity (Bridoux 1998; Westrelin and Bourdelot, 2001). However, figure $6 \mathrm{a}$ and $6 \mathrm{~b}$ reveal that a rather poor correlation is obtained between these two parameters and coagulant requirement, especially when only jar-tests carried out with CSO are taken into account. Likewise, the plot of OCC versus effluent initial $\mathrm{pH}$ shows considerable scatter (fig. 6c). In contrast, the optimum coagulant concentration is linearly correlated with CSO initial conductivity for both CLARFER and WAC HB. It must be pointed out that this correlation includes the results obtained with dry weather sewage (fig. 
6d), and that the coagulant concentration used to treat CSO, either storm or weak rain events, was always less than that required to treat dry weather sewage. Furthermore, the optimal dosage in WAC HB is consistently lower, though slightly, than that in ferric chloride, which confirms the greater effectiveness of the aluminum-based coagulant.

The straight lines obtained between coagulant requirement and CSO conductivity are actually an indirect consequence of a proportional relationship between total alkalinity and conductivity (inset of figure 6d). Such a linear relationship is rather unexpected. By definition, alkalinity is a measurement of the water acid-neutralizing capacity, and for surface waters, primarily depends on carbonate, bicarbonate, and hydroxide content. On the other hand, conductivity reflects the presence of all ionic species. The most straightforward explanation is that carbonates represent a major component in CSO conductivity, but such an hypothesis requires further scrutiny. The linear correlation between optimal coagulant concentration and CSO total alkalinity corroborates early research in coagulant dosing (Morison, 1916), indicating that turbidity has little effect on coagulant dosage compared to alkalinity. The slope, close to $1 \mathrm{~mol} / \mathrm{eq}$, suggests that the coagulant species are not fully hydrolyzed at optimal dosage, which is consistent with previous EXAFS investigations indicating that poorly polymerized Fe species are found in flocs at OCC (Vilgé-Ritter et al., 1999; El Samrani et al., 2004b). Finally, as shown in figure 7, the range of optimal dosing is also dependent on alkalinity, and hence on conductivity, which provides a further way for controlling CSO coagulation.

\section{CONCLUSION}

CSO chemical coagulation was investigated with both ferric chloride and prehydrolyzed aluminum coagulants. Both coagulants were found to provide an effective clarification, even though the required concentration in aluminum-based coagulant was always slightly less on a molar basis. Excellent heavy metal elimination was achieved within a narrow range of coagulant around OCC. Close examination of jar-test curves suggested a preferential removal of some heavy metal carriers by the coagulant species.

CSO quality was found to be very unsteady during wet weather events, and to strongly affect the coagulant dose yielding an acceptable removal of turbidity and heavy metals. Total alkalinity was shown to be the main factor determining the optimal coagulant concentration 
and the width of the coagulation zone. A linear correlation between OCC and conductivity provided a convenient guideline for rapidly adjusting coagulant demand in industrial practice. Further work is required to assess the validity of such linear relationship, as the need for a precise monitoring of coagulant dosage is a concern in most coagulation treatments.

Acknowledgements. This study was funded by Grand Nancy Urban Community. We gratefully acknowledge the technical support for field studies provided by P. Robaine. We also wish to thank the staff of SARM (CRPG - UPR 80), where ICP analyses were carried out.

\section{REFERENCES}

ASSTEE. Reglementation et traitement des eaux destinées à la consommation humaine. ASSTEE editor, 472p.

Badard M., Beutler E., Binot P., Boissonade G., Delsalle F., Gommery L., Haegel D., Issock JP., Delville J-F., Lion M., Rousse A. and Sibony J. (1994). Dépolluer les eaux pluviales, Contribution à l'élaboration d'une stratégie. Ouvrage collectif OTV. Lavoisier TEC\&DOC, $349 \mathrm{p}$.

Bebie J., Schoonen M.A., Fuhrmann M., Stongin D.R. (1998) Surface charge development on transition metal sulfides: an electrokinetic study. Geochim. Cosmochim. Acta 62(4), 633-642.

Bridoux G., Villeroux A., Riotte M. and Huau M. (1998). Optimized lamellae settling process for runoff water treatment. Novatech. 1, 429-436.

Chander S. and Fuerstenau D.W. (1979) Interfacial properties and equilibria in the apatiteaqueous solution system. J. Colloid Interface Sci. 70(3), 506-514.

Chebbo G., Mouchel J.M., Saget A. and Gousailles M. (1995). La pollution due aux rejets urbains par temps de pluie: flux, nature et impacts. TSM 90, 796-806.

Cole W.C. and Yonge D.R. (1993). Sediment and contaminant removal by dual-purpose detention basins. Washington State Transportation Center Report. 
Delporte C., Pujol R. and Vion P. (1995). Optimized lamellae settling for urban storm water waste. Wat. Sci. Tech. 32, 127-136.

Ellis J.B. and Revitt M. (1982). Incidence of heavy metals in street surface sediments: solubility and grain size study. Wat, Air, Soil pollut. 17, 87-100.

El Samrani A.G., Lartige B.S. Ghanbaja J., Yvon J. and Kohler A. (2004a). Trace element carriers in combined sewer during dry and wet weather: an electron microscope investigation. Wat. Res. 38, 2063-2076.

El Samrani A.G., Lartiges B.S., Montargès-Pelletier E., Kazpard V., Barrès O. and J.Ghanbaja. (2004b) Clarification of municipal sewage with ferric chloride: the nature of coagulant species. Wat. Res.38, 756-768.

Forniasero D., Eijit V., Ralston J. (1991) An electrokinetic study of pyrite oxidation. Colloids Surf. 62, 63-73.

Ghosh M., Amirtharajah A. and Adin A. (1994). Particle destabilization for tertiary treatment of municipal wastewater by filtration. Wat. Sci. Technol. Vol. 30 (9), 209-218.

Gregory J. and Dupont V. (2001). Properties of flocs produced by water treatment coagulants. Wat. Sci. Technol. 44, 231-236.

Gromaire-Mertz M-C., Chebbo G. and Saad M. (1998). Origins and characteristics of urban wet weather pollution in combined sewer systems: the experimental urban catchment «le Marais « in Paris. Wat. Sci. Technol. 37, 35-43.

Gromaire M.C., Garnaud S., Saad M. and Chebbo G. (2001). Contribution of different sources to the pollution of wet weather flows in combined sewers. Wat. Res. 35 (2), 521-533.

Grout H., Wiesner M. and Bottero J-Y. (1999). Analysis of colloidal phases in urban stormwater runoff. Environ. Sci. Technol. 33, 831-839. 
Gruber G., Winkler S., and Pressl A. (2005) Continuous monitoring in sewer networks: an approach for quantification for pollution loads from CSO's into surface water bodies. Wat. Sci. Technol., 52(12) 215-23.

Hamilton R.S., Revitt D.M. and Warren R.S. (1984). Levels and Physicochemical associations of $\mathrm{Cd}, \mathrm{Cu}, \mathrm{Pb}, \mathrm{Zn}$ in road sediments. Sci. Tot. Environ. 33, 59-74.

Herbert JR R. (1996). Metal retention by iron oxide precipitation from acidic ground water in Dalarna, Sweden. Appl. Geochem. 11, 229-235.

Jung A.-V., Chanudet V., Ghanbaja J., Lartiges B.S., Bersillon J.-L. (2005) Coagulation of humic substances and dissolved organic matter with a ferric salt: an electron energy loss spectroscopy investigation. Wat. Res. 39, 3849-3862.

Kazpard V., Lartiges B.S., Frochot C., d'Espinose de la Caillerie J.B., Viriot M.L., Portal J.M., Görner T., Bersillon J.-L. (2006). Fate of coagulant species and conformational effects during the aggregation of a model of a humic substance with $\mathrm{Al}_{13}$ polycations. Wat. Res. 40, 19651974.

Lainé S., Thierry P., Baron J., Robert P. and Tabuchi J-P. (1998). Physico-chemical and bacteriological pollution removal in urban stormwater by dissolved air flotation-filtration-UV disinfection. Novatech. 1, 371-378.

Laurensot F. (1998). Caractérisation de la charges métallique des eaux de temps de pluie, Rapport final : phase II : contribution des différents réservoirs à la pollution des eaux de temps de pluie et impact du balayage mécanisé sur la qualité des eaux de ruissellement, LHRSPNANCIE- Communauté Urbaine du Grand Nancy- AERM-Ville de Nancy, 45p.

Marchand A., Badot R., De Belly B. and Romain M. (1993). Les bassins de retention des eaux pluviales-Mode d'emploi. NANCIE, 222p.

Marsalek J., Rochfort Q., Mayer T., Servos M., Dutka B., Brownlee B. (1999). Toxicity testing for controlling urban wet-weather pollution: advantages and limitations. Urban Wat. 1, 91-103. 
Martinez C. and Mcbride M. (1998). Solubility of $\mathrm{Cd}^{2+}, \mathrm{Cu}^{2+}, \mathrm{Pb}^{2+}$, and $\mathrm{Zn}^{2+}$ in aged coprecipitates with amorphous iron hydroxides. Environ. Sci. Technol. 32, 743-748.

Morison J. (1916). The dose of Alum for the clarification of water by precipitation. Indian. J. Med. Res. 3, 565-613.

Morrison G.M., Revitt D.M., Ellis J.B., Svensson G., Balmer P., (1984) Variations of dissolved and suspended solid heavy metals through an urban hydrograph. Environ. Technol. Lett. 7, 313-318.

Nascimento N.O., Ellis J-B., Baptista M.B., and Deutsch J.-C. (1999). Using detention basins : operational experience and lessons. Urban Wat. 1, 113-124.

Paulson C. and Amy G. (1993). Regulating metal toxicity in stormwater. Wat. Environ. Technol. July, 44-49.

Plum V., Dahl C.P., Bentsen L., Petersen C.R., Napstjert L., Thomsen N.B. (1998) The Actiflo method. Wat. Sci. Technol. 37(1), 269-275.

Pugh R.J. and Tjus R. (1987) Electrokinetic studies on Cu(II) hydroxy coated zinc sulfide particles. J. Colloid Interface Sci. 117, 231-241.

Richmond W.R., Loan M., Newman M., Parkinson G.M. (2005) Zinc sulfide as a solid phase additive for improving the processing characteristics of ferrihydrite residues. Hydrometallurgy $78,172-179$.

Rodier J. (1984). L'analyse de l'eau, eaux naturelles, eaux résiduaires, eau de mer. Chimie, Physico-chimie, Bactériologie, Biologie. $7^{\text {ème }}$ édition, Dunod, 1365p.

Spadini L., Manceau A., Schindler P. and Charlet L. (1994). Structure and stability of Cd2+ surface complexes on ferric oxides; 1. Results from EXAFS Spectroscopy. J. Colloid Interface Sci. 168, 73-86. 
Suarez J., and Puertas J. (2005) Determination of COD, BOD, and suspended solids loads during combined sewer overflow (CSO) events in some combined catchments in Spain. Ecological Engineering 24, 201-219.

Tait S., Rushforth P. and Saul A. (1998). A laboratory study of the erosion and transport of cohesive-like sediment mixtures in sewers. Wat. Sci. Technol. 37, 163-170.

Vilgé-Ritter A., Rose J., Masion A., Bottero J.-Y., Lainé J.-M. (1999) Chemistry and structure of aggregates formed with Fe-salts and natural organic matter. Colloids Surf. 147, 297-308.

Westrelin J-L and Bourdelot J-C. (2001). High rate primary treatment of waste and stormwaters with DENSADEG. Second World Water Congress of the International Water Association (IWA), Berlin- Germany.

\section{Figure Captions}

Figure 1: Comparison of ferric chloride $(\bullet)$ and WAC HB (O) performances for a CSO event of high alkalinity (0.53 meq/L). (a) Residual turbidity versus coagulant concentration. (b) Sediment volume versus coagulant concentration. Inset of fig. 1a: Variation of $\mathrm{pH}$ as a function of coagulant dosage ( $\mathbf{a})$ ferric chloride, ( $\square$ ) WAC HB. The solid bar represents the optimal coagulant concentration; the hatched bar represents the restabilization concentration for ferric chloride.

Figure 2: Comparison of ferric chloride and WAC HB performances for a CSO of low alkalinity (0.049 meq/L). (a) and (c) Residual turbidity and electrophoretic mobility versus coagulant concentration. (b) et (d) Sediment volume (ם) and $\mathrm{pH}(\diamond)$ versus coagulant 
concentration. The solid bar represents the optimal coagulant concentration; the hatched bar represents the restabilization concentration for ferric chloride.

Figure 3: Variation of $\mathrm{Cu}, \mathrm{Pb}, \mathrm{Zn}$, and $\mathrm{Cr}$ supernatant concentrations in soluble $(\mathrm{O})$ and suspended solids $(\bullet)$ fractions as a function of coagulant dosage. The broken line represents the evolution of residual turbidity with coagulant concentration. The residual suspended solid concentration is obtained by difference between the total metal concentration and the soluble metal concentration.

Figure 4: Evolution of jar-test curves during a CSO event. (a) Coagulation with ferric chloride. (b) Coagulation with WAC HB. The insets show the variation of optimal dosage $\left(\mathrm{Fe}_{\text {opt }}\right.$ or $\left.\mathrm{Al}_{\mathrm{opt}}\right)$ et restabilization concentration $\left(\mathrm{Fe}_{\mathrm{r}}\right.$ or $\left.\mathrm{Al}_{\mathrm{r}}\right)$ as a function of time.

Figure 5: Evolution of CSO physico-chemical characteristics as a function of time: (a) Total suspended solids. (b) Turbidity. (c) pH. (d) Conductivity. The variation of flow rate during the CSO event is indicated in each graph.

Figure 6: Optimal coagulant concentration as a function of (a) Suspended solids, (b) CSO turbidity, (c) initial pH, (d) conductivity. Open circles (O): ferric chloride. Filled circles (๑): WAC HB. The inset of fig. $6 \mathrm{~d}$ shows the linear relationship between Total alkalinity and conductivity. The data points above the horizontal line were obtained from jar-tests carried out with sewage (CSF).

Figure 7: Range of optimal dosing versus CSO Total alkalinity for ferric chloride. The inset shows the range of optimal dosing for a given jar-test.

Table 1: Physico-chemical characteristics of CSO events and of sewage (CSF): means and standard deviations. $\mathrm{n}$ indicates the number of samples used to calculate the statistics.

\begin{tabular}{|c|c|c|c|c|c|c|}
\hline & \multicolumn{6}{|c|}{ Mean and standard deviation } \\
\hline $\begin{array}{l}\text { Sample } \\
\text { type }\end{array}$ & $\begin{array}{c}\mathrm{SS} \\
\mathrm{mg} / \mathrm{L}\end{array}$ & $\begin{array}{c}\mathrm{VS} \\
\mathrm{mg} / \mathrm{L}\end{array}$ & $\begin{array}{c}\text { Turbidity } \\
\text { (NTU) }\end{array}$ & pH & $\begin{array}{l}\text { Conductivity } \\
\qquad(\mu \mathrm{S} / \mathrm{cm})\end{array}$ & $\begin{array}{c}\text { Total } \\
\text { Alkalinity } \\
(\mathrm{meq} / \mathrm{L})\end{array}$ \\
\hline $\begin{array}{l}\text { Sewage } \\
\text { (dry }\end{array}$ & $\begin{array}{c}864 \pm \\
87.6\end{array}$ & $\begin{array}{c}570 \pm \\
82.7\end{array}$ & $\begin{array}{l}145 \pm \\
30.76\end{array}$ & $\begin{array}{c}7.82 \\
\pm\end{array}$ & $889 \pm 49.82$ & $\begin{array}{l}1.48 \pm \\
0.164\end{array}$ \\
\hline
\end{tabular}




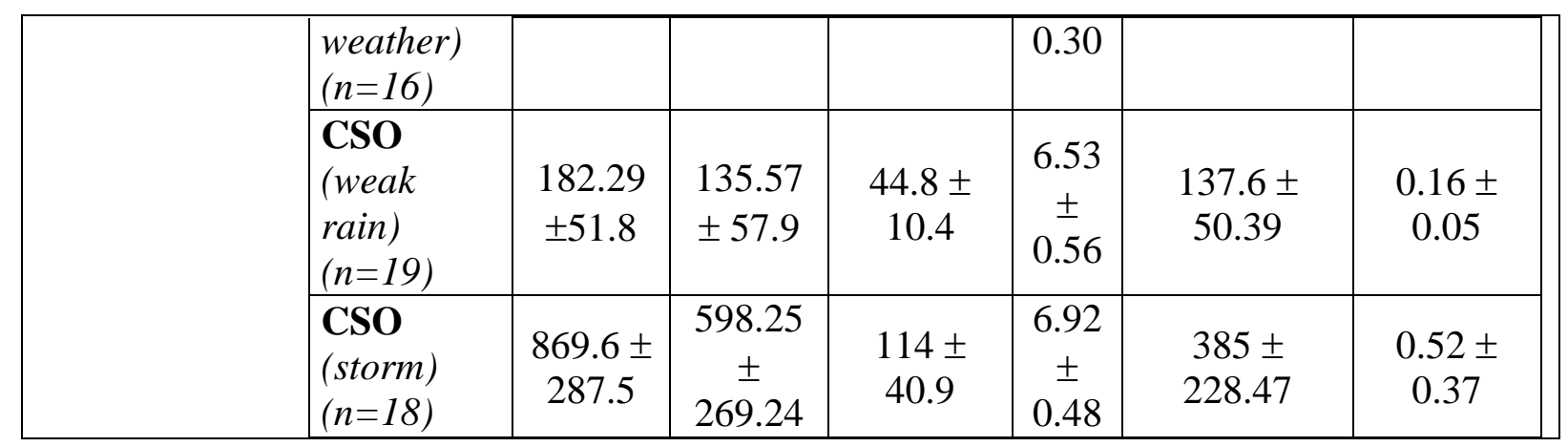

